REGE

25,4

Received 2 January 2018 Revised 16 July 2018 10 August 2018 Accepted 14 August 2018

\section{Workaround behaviour in information systems research}

\author{
Aline de Vargas Pinto, Antônio Carlos Gastaud Maçada and \\ Gabriela Labres Mallmann \\ Programa de Pós Graduação em Administração, \\ Universidade Federal do Rio Grande do Sul, Porto Alegre, Brazil
}

\begin{abstract}
Purpose - The purpose of this paper is to provide an analysis of the studies about workaround behavior in the Information Systems (IS) area, addressing its positive and negative aspects and raising the key related issues. Design/methodology/approach - A systematic literature review was conducted to verify how workaround behavior has been approached in IS studies. A qualitative method was adopted and implemented in two stages: selection of articles from the time period 2007-2017 in the databases Web of Science, ScienceDirect and Scopus and analysis of the selected articles.

Findings - The results showed that many studies have been concerned with identifying the principal reasons for the manifestation of workaround behavior and the measures taken to reduce its impacts. Many studies from international journals examined the implementation of an ERP along with the workaround behavior. The need to expand the national studies on workaround behavior is emphasized, because the majority of the identified studies are international.

Research limitations/implications - The key limitation is related to the period of analysis, because only articles published since 2007 were selected.

Practical implications - This paper contributes to both theory and practice, bringing relevant concepts about workaround behavior, and corroborating the importance of the studies on workaround in the IS area. The literature review of the 20 articles analyzed reveals the main features in each article, such as theoretical and methodological aspects that support the research. Based on this analysis, a conceptual map was developed presenting the most relevant points about workaround behavior, where the causes, the negative and positive consequences, the types of solutions and the organizational and individual impacts are presented.

Originality/value - Research into workaround behavior has increased in recent years, however very few studies have been conducted in Brazil. To the best of the authors' knowledge, no articles regarding Brazil and this subject were published between 2007 and 2017. Thus, this paper seeks to redress this imbalance.
\end{abstract}

Keywords IT management, Information systems (ISs), Workaround behaviour

Paper type Literature review

\section{Introduction}

Organizations are increasingly seeking to improve the level of productivity of their employees, especially with the use of information systems (ISs) and mobile technologies (MT). However, the new information technology (IT) management policies, Bring Your Own Device (BYOD) for example, which allows employees to use their personal devices while in the organization and to connect them to the corporate network, and the concern with the use of non-authorized technologies inside the workspace, called shadow IT, have manifested the workaround behavior by the employees more intensely (Dulipovici and Vieru, 2016).

The investments in ITs have been increasing in the organizations, aiming to standardize the work processes and to gain improvements in the performances, with higher productivity (Röder et al., 2015). Estimates show that, in 2018, the global expenses with IT should reach a

(C) Aline de Vargas Pinto, Antônio Carlos Gastaud Maçada and Gabriela Labres Mallmann. Published in Revista de Gestão. Published by Emerald Publishing Limited. This article is published under the Creative Commons Attribution (CC BY 4.0) licence. Anyone may reproduce, distribute, translate and create derivative works of this article (for both commercial and non-commercial purposes), subject to full attribution to the original publication and authors. The full terms of this licence may be seen at $\mathrm{http} / / /$ creativecommons.org/licences/by/4.0/legalcode 
total of US\$ 3.7tn, equivalent to an increase of 4.5 percent in comparison to 2017. The investments are driven and directed toward cloud computing, MT and internet of things that help the organizations to improve employees' productivity, and bring implications such as enhancing the workaround behavior (Gartner, 2018).

The workaround behavior was initially defined as non-standard procedures used by users/operators to compensate the deficiencies found in the IS (Courtright et al., 1988). Subsequently, other authors have brought new definitions to the workaround behavior, defining it as informal methods to compensate the inability to obtain necessary data or the capability of using alternative processes to avoid perceived blockage in the workflow, with the possibility of using an extension or a resource that is non-existent in the system (Petrides et al., 2004; Vogelsmeier et al., 2008).

For the users, the workaround behavior allows the overcoming of impact procedures and issues at work being composed of temporary practices (Alter, 2014). However, the organization is often not aware that the employees are applying other solutions for the job completion. The workaround behavior can have different results for the employees and for the organization, because the adoption and use of alternative solutions are individual, according to the necessities and abilities of each user, and the result of its adoption may not be desired by the organization (Drum et al., 2016).

The employees will use the IS adopted by the organization if they identify quality in the system based on the desired characteristics of the technology itself, considering usability aspects such as ease of use, efficiency, navigation and reliability (Petter et al., 2013). In a recent investigation, the workaround behavior was analyzed by Laumer et al. (2017), using the following dimensions: quality of the system, quality of the service and quality of the information (representative and contextual), as prior to user satisfaction and workaround behavior. The model's dependent variable has evaluated the benefits in productivity and in the work performance through workaround behavior. However, the research did not fill all the gaps and the opportunities of research on IS workaround behavior, some of which are listed in this research as recommendations for future research.

Thus, the aim of the present study is to verify how the workaround behavior has been approached in IS studies, verifying its applicability and presenting guidelines for future research. The importance of this research in the theoretical and practical scope focuses on gathering relevant information about the workaround behavior, bringing up positive and negative aspects of the manifestation of this behavior. Besides, no Brazilian study has been identified on workaround in the IS area in the databases consulted (Web of Science, Scopus, Science Direct), showing a research gap on this theme in Brazil.

This paper is structured as follows. Section 2 presents a literature review about aspects of the workaround behavior and its use in the IS researches. Section 3 approaches the method that was used. Section 4 presents the results and, lastly. Section 5 presents the conclusions and guidelines for future researches.

\section{Literature review on workaround}

IT area allows to organizations high capability to extend, acquire, manipulate and communicate information, being a strategic and fundamental resource to companies, because it ensures the quality of information on the decision-making process, providing operational and strategic benefits to the companies (Rikhardsson and Dull, 2016). Once a certain technology is adopted in the business process, the company's capacity for growth tends to increase (Xiong and Qureshi, 2012). Thus, IS allows filtering the most relevant information to the business, taking into account that around 80 percent of information in organizations are not structured and are found in websites, text documents, spreadsheets, presentation slides and many other formats (Alalwan and Weistroffer, 2012).

Workaround behaviour 
REGE 25,4

432
The deployment of an IS can be beneficial to organizations. However, the degree of employees' use of this system will depend on the satisfaction with the system and the level of support assigned to it. The user dissatisfaction with the system adopted by the company leads the employee to find alternative solutions to those prescribed by the IT department (Laumer et al, 2017). At the organizational level, the benefits that an organization expects when implementing an IS decrease when the employees establish alternative solutions (Petrides et al., 2004).

Alternative solutions are the use of any system that deviate from the prescribed policies and processes, which could be planned solutions, when the system does not meet the business' needs, or non-planned solutions to meet an immediate and specific need (Drum et al., 2017). Managers believe that alternative solutions are temporary practices implemented and used to deal with uncertainties matters right after the implementation of a system, with the belief that these practices should decrease over time. However, previous research suggests that these practices, in fact, increase over time instead of disappearing (Azad and King, 2012). One of the first authors to study IS use after its implementation was Gasser (1986). This study shows situations in which the IS did not meet the processes and requisites of the task work that leads to the manifestation of alternative solutions called workarounds.

IS literature conceptualizes the workaround behavior as the employees' decision to adapt and improvise the organizational IS in a way that makes it possible to overcome any anomalies and restrictions that do not allow the work performance to be complete and effective (Alter, 2014; Malaurent and Avison, 2015). The workaround behavior is considered a way for users to get involved with the system while not conforming to the prescribed "rules of engagement," leading them to resort to alternative solutions (Petrides et al., 2004; Kobayashi et al., 2005) or as a mean of neutralizing the perception of loss of power and identity with the introduction of a new IS (Alvarez, 2008).

Workaround behavior is often seen as negative. However, some authors present beneficial aspects from its manifestation. From a positive point of view, workaround behavior is considered a normal part of an IS implementation process and, as such, provides sources for future improvements (Safadi and Faraj, 2010). Workaround behavior can be much more than acts of resistance, being, actually, necessary solutions to support the accomplishment of activities (Azad and King, 2012).

From a negative point of view, workaround behavior can generate risks, inefficiency or errors and may have an impact on subsequent work activities, for example, when mistakes are made (Boudreau and Robey, 2005; Gasparas and Monteiro, 2009). Although alternative solutions are often temporary practices to deal with immediate problems, there is some increasing evidence that such alternative practices can become permanent forms of use (Azad and King, 2012; Orlikowski, 2008).

Therefore, the main reasons for the workaround behavior adoption in IS are users and managers satisfaction, and the use of alternative solutions can have both positive and negative consequences (Laumer et al., 2017). In many situations, organizations are not aware that employees are embracing workarounds to get the job done, as they are informal temporary practices for handling exceptions in the workflow. The satisfaction of the users with the IS is an essential indicator of the success of the system, that is, the more satisfied the user is with the system, the less prone they will be to manifest the workaround behavior, which is caused by the lack of meeting their expectations with the company system (Vaezi et al., 2016).

\section{Method}

We performed a systematic literature review (SLR) based on the model proposed by Biolchini et al. (2007), which includes the following phases: planning, execution and analysis 
of the results. In addition, the present study follows the guidelines proposed by Webster and Watson (2002) that emphasize that an effective literature review creates a solid foundation for knowledge advance, and it is fundamental for the strengthening of IS research. According to those authors, the research should provide elaborate definitions of their key variables, define the limits of their work, indicate which literature and areas of study were used, clearly present the contributions of the article, and, finally, perform an investigation of all the articles published and not only those published in the most respected journals in the area.

\subsection{Planning and execution}

To carry out the research, first, the journals cited in the Association for Information Systems (AIS) "basket" of eight top IS journals were consulted. This list indicates eight journals with greater power of impact in the IS area. Twelve articles were found in these journals, considered to be the most relevant in the area, while the rest of the articles were found in other journals or congress articles. The search and selection of articles were carried out through three large databases (Science Direct, Scopus and Web of Science), from April 10 to 25,2017 . The publications of the last ten years, from 2007 to 2017, were analyzed in order to select the recent literature on the subject, being that the temporal delimitation. The initial searches in the databases resulted in 5,068 articles, which were later filtered by the occurrence of the term workaround in the abstract, keywords and title, resulting in 249 articles. We found 32 articles that linked the term workaround with the IS area. The search was conducted in English since all publication sites were international, and no publication in Portuguese was found.

The first search was performed in ScienceDirect, where 111 articles were found. The second database was Scopus, where a total of 104 articles were selected for analysis. Finally, in the Web of Science database, the field "Information Science Library Science" was filtered, where 34 articles were analyzed. From this analysis, 32 articles were selected, and, after excluding repeated articles, there were 20 articles left. Table I allows a better visualization of the search criteria used to select the articles.

The articles which did not meet the selection criteria established by Table I were excluded from the analysis. Therefore, all of the preselected articles from the databases were analyzed, and a thorough search of the Table's I keywords was made on the text. In case there were none of these keywords in the article's title, abstract or keywords, the article was

\begin{tabular}{ll} 
Search Criteria & Description \\
\hline $\begin{array}{l}\text { Keywords } \\
\text { Data base }\end{array}$ & $\begin{array}{l}\text { Workaround, Information Systems, IS } \\
\text { Science Direct, Scopus e Web of science }\end{array}$ \\
$\begin{array}{l}\text { Article selection } \\
\text { criteria }\end{array}$ & $\begin{array}{l}\text { Contain the word workaround in the title, } \\
\text { abstract or keywords and be connected } \\
\text { to the area of information systems }\end{array}$ \\
$\begin{array}{l}\text { Search period } \\
\text { 10 years (2007-2017) }\end{array}$ &
\end{tabular}

Scopus

Science Direct

Web of Science

Total

Total excluding duplicate articles: 20

Workaround Workaround in Workaround

(2007-2017) title, abstract or + IS

$\begin{array}{crr} & \text { keywords } & \\ 793 & 104 & 16 \\ 3.795 & 111 & 5 \\ 480 & 34 & 11 \\ 5.068 & 249 & 32\end{array}$

Workaround behaviour
Table I.

Search criteria for articles 
REGE

25,4

434

dismissed. In order to assess whether the research was in the IS area, an analysis was made whenever the term workaround appeared. The preselected articles excluded from the analysis addressed the workaround theme. However, its majority was composed of medical field works, not associated with the IS area.

The articles were reviewed based on the abstract, the introduction and the conclusions, according to Biolchini et al. (2007), in order to verify the framework and to confirm the Table I data. The last stage is composed by the analysis of the results presented below.

\subsection{Results analysis}

The third stage proposed by Biolchini et al. (2007) is the article's analysis. This stage aimed to gather information to support the study. Each article was analyzed individually, in order to extract the main characteristics out of each one. The presentation and discussion of the results are highlighted in the following section.

\section{Results presentation and discussion}

This section presents and discusses the obtained results in this study, which analyzes how the selected articles relate the concept of workaround in IS.

\subsection{Characterization of the selected articles}

According to the selection criteria established in Section 3, twenty articles were chosen to be part of the research and their main characteristics are listed in Table II.

All the articles were selected from international journals. The journals with the highest rate of publications on workaround were the European Journal of Information Systems, corresponding to 30 percent of the analyzed articles, and the Information Systems Journal, with 15 percent. Both are considered journals of high impact factor in the IS area. The workaround theme has been studied in many countries, especially in the USA, which published 25 percent of the selected articles. Figure 1 shows the countries and the respective percentage from the publications of the 20 articles analyzed.

From the sampled articles, Alter (2014) was the most quoted author with 157 citations, followed by Alvarez (2008) with 135 citations. However, the authors with more publications on the theme are Azad and King (2008, p. 212), Malaurent and Avison $(2015,2016)$ and Drum et al. (2016, 2017), respectively.

In Table III, the frequency of publications of the articles on workaround is presented.

The year with the highest number of publications was 2016, and the number decreasing in 2017. Table III allows to assess that the number of publications addressing workaround in IS has increased in the last years, showing that the subject has been receiving bigger attention. Below are presented the obtained results from the analysis of the articles' content.

\subsection{Workaround in the IS area}

From the 20 analyzed articles, 85 percent are empirical (articles: 1, 2, 3, 4, 6, 7, 8, 9, 10, 11, 12, $14,15,16,18,19$ and 20 ) and only 15 percent are theoretical (articles: 5,13 and 17). Few articles aimed to accomplish a theoretical study about the workaround theme in the IS area. From the 20 articles analyzed, 65 percent deal with case studies with the purpose of verifying how the manifestation of workaround behavior can impact one or more organizations, identifying the main reasons leading to the manifestation of the workaround behavior and how it can be avoided. Many articles approached workaround along with other themes that can be seen in Figure 2, which presents a graphic with the number of occurrences of some of the main themes related to workaround researches on IS.

Figure 2 was developed from the analysis of the abstracts and keywords of the selected articles. We identified that 1 article is connected to more than a theme, as article 10, which 


Title
1 Information quality, user satisfaction,
and the manifestation of workarounds:
a qualitative and quantitative study
of enterprise content management
system users

2 A multiple case study on the nature and management of shadow information technology

3 Workarounds in an SAP environment: Impacts on accounting information quality

4 Examining the intended and unintended consequences of organizational privacy safeguard

5 Solving misfits in ERP implementations by SMEs

6 Understanding individual user resistance and workarounds of enterprise social networks: the case of Service Ltd

7 Creating Smart Governance: the key to radical ICT overhaul at the City of Munich

8 Reconciling global and local needs: A canonical action research project to deal with workarounds

9 Walking a mile in their shoes: user workarounds in a SAP environment

10 Feral Information Systems, Shadow Systems, and Workarounds - A Drift in IS Terminology

11 From an apparent failure to a success story: ERP in China-Post-

implementation

Author/year

Laumer et al. (2017)

(2017)

Journal/Conference

European Journal of Information Systems

Base

Science

Direct

Zimmermann et al. (2017)

Drum et al. (2017)

Parks et al. (2017)

Beijsterveld and Groenendaal (2016)

Choudrie and

Zamani (2016)

Scholl and Alawadhi

(2016)

Malaurent and

Avison (2016)

Drum et al. (2016)

Lund-Jensen $e t$ al.

(2016)

Malaurent and

Avison (2015)

12 Toward an implementation framework for Foshay and business intelligence in healthcare

Kuziemsky (2014)

13 Theory of workarounds

Alter (2014)

14 I Did It My Way: social workers as secondary designers of a client information system

Huuskonen and

Vakkari (2013)

Journal of Information Scopus Systems

\section{Journal of Accounting Scopus} and Organizational

Change

European Journal of Information Systems

Scopus/Web of Science

Information Systems

Journal

Journal of Information

Technology

Scopus/Web of Science

Scopus/Web

of Science

Scopus

Information Systems

Journal

Scopus/Web of Science

International Journal of Scopus Accounting and

Information

Management

Procedia Computer Science

Science

Direct

International Journal of Scopus/Web

Information of Science/

Management Science

Direct

International Journal of Scopus

Information

Management

Communications of the Scopus

Association for

Information Systems

Information Processing Web of

and Management

Science/

Science

Direct

Scopus/Web

Scopus/Web

Azad and King

(2012)

practices in a Mediterranean country: an examination of two organizations

17 Workarounds in the use of IS in healthcare: a case study of an electronic medication administration system
Yang et al. (2012) of Science

European Joumal of

Information Systems

of Science

International Journal of Scopus/

Human-Computer Science

Studies
Exomation Systems
Direct

(continued)
Workaround behaviour 
REGE

25,4

436

19 Enacting computer workaround practices Azad and King within a medication dispensing system (2008)

Author/year

Journal/Conference

Base

18 Post-ERP Feral System Taxonomy: a Urus et al. (2011) European Conference Web of Manifestation From Multiple Case Studies

on Information

Science

Management and

Evaluation

European Journal of $\quad$ Web of

Information Systems Science/

20 Examining technology, structure and identity during an Enterprise System

Alvarez (2008)

Information Systems

Journal

Scopus

implementation

Web of

Science/

Scopus

Table II.

Source: Developed by the authors

Figure 1.

Publications origin

\begin{tabular}{llll}
\multicolumn{4}{c}{ Countries } \\
$\square$ Germany & $\square$ USA & France & $\square$ Canada \\
$\square$ UK & $\square$ The Netherlands & $\square$ Finland & $\square$ Greece \\
$\square$ Norway & $\square$ Denmark & $\square$ Singapore & $\square$ Australia \\
$\square$ Lebanon & & &
\end{tabular}

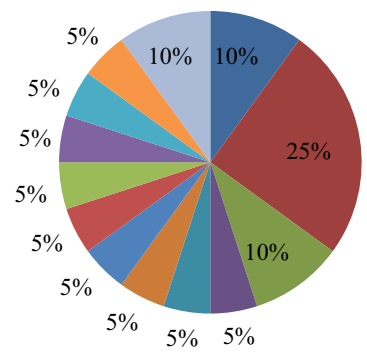

Source: Developed by the authors

\begin{tabular}{lc}
\hline Year & Frequency \\
\hline 2007 & 0 \\
2008 & 2 \\
2009 & 0 \\
2010 & 0 \\
2011 & 0 \\
2013 & 1 \\
2014 & 3 \\
2015 & 1 \\
2016 & 2 \\
Source: Developed by the authors & 1 \\
& \\
\end{tabular}

\section{Table III.}

Frequency of publications per year

Source: Developed by the authors 


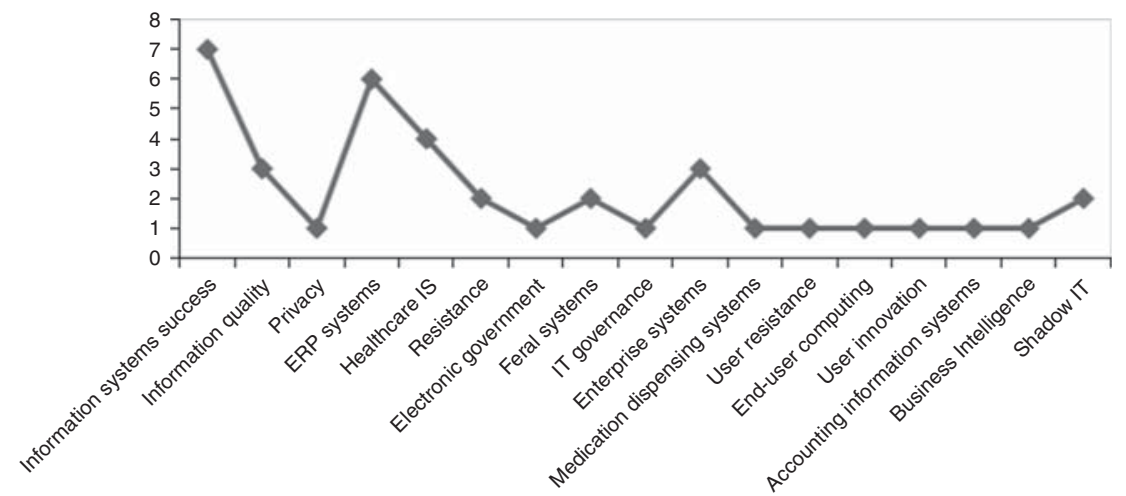

Source: Developed by the authors
Workaround behaviour

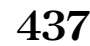

approaches the shadow IT and ERP themes. Figure 2 demonstrates the quantification of the themes related to the workaround behavior, showing a connection between them. As an example, the widely utilized ERP theme is mentioned. This occurrence is justified by the many implementations of ERP that are not fitting with the employees' needs, lacking the proper planning, which leads to the dissatisfaction of workers with the system. When planning to implement an ERP system, the company must decide if it wants to adjust its business processes to the ERP system or if the ERP system must be adjusted to their business processes, in order to avoid an unsuccessful implementation, leading to misuse or abandonment of the system by employees.

Employees need to identify the desirable characteristics to the fulfillment of their jobs, as the quality of information and system, in order to utilize the company system. An employee who does not find certain attributes in the system will resort to alternative solutions, believing it may be the best way to overcome the identified obstacles in the system. Many companies adopt enterprise systems believing it is the best way to simplify operations and to improve the decision-making process through information access. However, from employees' point of view, the system does not always fulfill their needs and so they resort to other means to accomplish their jobs, utilizing other softwares or resources, such as Excel sheets. Therefore, the adoption of alternative solutions by the employees leads to unnecessary IS investments by the companies and to the implementation of systems that will not be fully utilized due to the provided information incapacity to fulfill the needs to accomplish the tasks and the decision-making process (Drum et al., 2016). Figure 3 shows the word cloud of abstract, title and keywords.

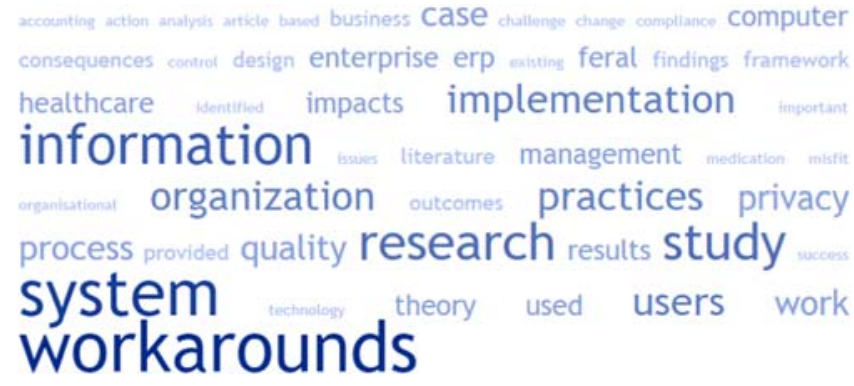

Source: Developed by the authors

Figure 3.

Abstract, title and keywords word cloud 
REGE 25,4
The words with the highest frequency on title, abstract and keywords were "workaround," "systems" and "information." Since the selection of the articles was filtered through the workaround study in the IS area, this outcome was expected. The context of workaround in IS, in which the use of alternative solutions is mostly motivated by the failure of the implementation or adoption of an enterprise system, is clear through the analysis of the word cloud. Many papers that studied alternative solutions in the ERP context (e.g. Urus et al., 2011; Malaurent and Avison, 2015; Beijsterveld and Groenendaal, 2016) showed that organizations are not planning the implementation in a manner that the system attended the needs of the employees. Another matter addressed in the articles is the lack of proper training, which leads to employees who do not know how to fully operate the technology.

The employees resort to other means to perform their tasks rapidly and easily as a way of surpassing the obstacles found in the system. The causes for the use of alternative solutions vary among the authors, it may be motivated by the ignorance of the technology's features, which leads to a resistance in usage (Laumer et al., 2017); by the lack of necessary attributes, such as the system and available informations' quality or an easy to use and trustworthy support service (Petter et al., 2013); by a barrier to the effective and simplified accomplishment of job tasks (Alojairi, 2017) or because the necessary information are limited (Huuskonen and Vakkari, 2013). Therefore, in the employees' point of view, the alternative solutions are essential and allow the fulfillment of tasks in a complete and effective manner. However, the organization sees these solutions as prejudicial to the security context. In the organizational level, the benefits an organization expects when implementing an IS diminishes when alternative solutions are established by the employees (Petrides et al., 2004). Cresswell et al. (2016) identified that the use of alternative solutions resulted in new risks, such as delay in the information access and difficulty in finding data and information.

Some methodological aspects also appeared in the word cloud, as "case," "literature," "paper," "research" and "framework." The majority of the analyzed studies are qualitative based on a case study, which explains the highlight on the word "case" in the cloud. It is usual for the papers to present its methodologies in the abstract so the reader can have a general idea about the article, which justifies the occurrence of methodological words in the word cloud. At last, as presented in Figure 3, the terms "health," "healthcare" and "medical" appeared in the word cloud, since five of the twenty analyzed studies were about workaround in IS in the health sector.

In order to enrich the articles' analysis, Table IV presents the theories identified in the selected articles for this review, classified in theories utilized mainly by the IS area, according to the website www.aisnet.org/ of The AIS, and the theories not as frequently observed in the studies of the area.

In total, 12 of the 20 articles analyzed used of theoretical lenses to support their arguments or to illustrate a connection between the proposed theme and a theory. The articles $2,7,10,11,14,17,18$ and 19 did not state the use of theories.

An example is the use of theories about the adoption and acceptance of technologies (Unified theory of acceptance and use of technology and Technology acceptance model), since the workaround behavior is manifested mostly by the users' dissatisfaction with a technology. Three articles used the theory of success model in IS by DeLone and McLean. The research developed by Laumer et al. (2017) used the key constructs in the DeLone and McLean's model and validated a measuring scale for the workaround behavior. Drum et al. (2016, 2017) used only the quality of accounting information in the SAP ISs' dimension.

The institutional theory was also one of the most cited. In the Azad and King (2012) research the authors argued that the IS researches usually address workaround as temporary phenomena. However, the authors claim that some alternative solutions may present an institutionalized behavior. On the other hand, Beijsterveld and Groenendaal (2016) made use of the institutional theory to explain the differences between imposed work structures and the voluntary structures. Furthermore, these authors approached the importance of the 


\begin{tabular}{|c|c|c|c|}
\hline Article & IS theories & Others theories & $\begin{array}{l}\text { Workaround } \\
\text { behaviour }\end{array}$ \\
\hline 1 & $\begin{array}{l}\text { Work systems theory } \\
\text { Delone and McLean IS success model }\end{array}$ & - & \\
\hline 3 & Delone and McLean IS success model & - & \\
\hline 4 & $\begin{array}{l}\text { Diffusion of innovations theory } \\
\text { Accountability theory }\end{array}$ & $\begin{array}{l}\text { Balance theory } \\
\text { Consumer theory } \\
\text { Emergent theory }\end{array}$ & 439 \\
\hline 5 & $\begin{array}{l}\text { Contingency theory } \\
\text { Institutional theory }\end{array}$ & - & \\
\hline 6 & $\begin{array}{l}\text { Institutional theory } \\
\text { Technology acceptance model } \\
\text { Unified theory of acceptance and use of technology }\end{array}$ & - & \\
\hline 8 & - & $\begin{array}{l}\text { Activity theory } \\
\text { Instrumental theory }\end{array}$ & \\
\hline 9 & Delone and McLean IS success model & - & \\
\hline 12 & $\begin{array}{l}\text { Socio-technical theory } \\
\text { Diffusion of innovations theory }\end{array}$ & $\cos 20$ & \\
\hline 13 & $\begin{array}{l}\text { Structuration theory } \\
\text { Agency theory } \\
\text { Work systems theory } \\
\text { Actor-network theory } \\
\text { Adaptive structuration theory } \\
\text { Theory of planned behavior }\end{array}$ & $\begin{array}{l}\text { Activity theory } \\
\text { Socio-materiality theory }\end{array}$ & \\
\hline 15 & Actor-network theory & - & \\
\hline $\begin{array}{l}16 \\
20\end{array}$ & Institutional theory & Speech Act Theory & $\begin{array}{l}\text { Table IV. } \\
\text { Theories mentioned }\end{array}$ \\
\hline \multicolumn{3}{|c|}{ Source: Developed by the authors } & in the articles \\
\hline
\end{tabular}

institutional theory's role, demonstrating that some actors become captive to their external institutional environment, because they supply a natural source of inspiration. Their study approaches the use of enterprising systems in a big organization of the service sector in order to examine the reasons why the users may choose to use or not IS, providing a solid base for the investigation of established institutional solutions.

Regarding other theories frequently approached by the articles, two of them presented the actor-network theory and work systems theory to analyze the workaround behavior. Monteiro et al. (2012) examine the actor-network theory as a way of verifying the performance through similar or equivalent practices to accomplish tasks and enable knowledge in the organizations. Alter (2014) only cites the theory as a suggestion to future research connected to the workaround theory, without, however, explaining why this theory must be studied along with the workaround behavior.

The work systems theory is approached by Alter (2014), who keeps the focus on all the work system, not only on technology or process. He recalls that changes may occur in relation to any element of the work system structure. Laumer et al. (2017) approach the theory's aspects by citing Alter (2014), who suggests that, in the work systems theory, the element of information of a work system should be analyzed in five different dimensions. Thus, Laumer et al. (2017) use DeLone and McLean's dimensions in their model of study. Furthermore, Table V presents the main results of the articles on the subject of workaround.

From the 20 articles analyzed, eight addressed implementation of ERP along with workaround behavior. These articles state that, after the implementation of ERP, the employees sought alternative solutions in account of finding and solving problems on the system. In terms of available IT, the software of Enterprise Resource Planning (ERP) is a solution broadly used, seeing as it can integrate a complete aggregate of organizational functions 


\section{REGE 25,4}

\section{Article Conclusions of articles with the term workaround}

1 The quality of information is important to assess end-user satisfaction and influence workaround behavior

2 Shadow IT, evolved as a type of workaround from nontransparent and unapproved end-user computing

3 Lack of studies on workaround, whose focus was the cause of the manifestation of workaround behavior

$4 \quad$ Workaround behavior can detract from the organization's privacy

5 The manifestation of workaround behavior leads the organization to adjust its ERP to employee satisfaction

6 The main reason for workaround behavior is the pressures that occur at work, which impedes the proper use of corporate social networks

7 It presents the importance of the successful review of the ICT governance model taking into account workaround practices

8 It presents the importance of business process management to deal with the manifestation of workaround behavior

9 Users see alternative solutions from other organizations' members as detrimental to the quality of accounting information, but see their own alternative solutions as critical to maintaining the quality of the process

10 The terms shadow IT, feral systems and workaround have common characteristics, but they have differences, mainly in relation to the time aspect

11 The lack of transparency of workaround behavior has led to the need to formalize measures

12 A structure was developed to define and prioritize the information needs of decision support in the context of specific health processes

13 Workaround is adopted to reduce the perceived restrictions by employees in the performance of their work

14 Workaround offers more control over information and saves time by overcoming the obstacles and failures of the organization's system

15 It points to the importance of making workarounds more flexible and reducing the degree of formalism and the amount of resources required

16 Workaround behavior is essential to make IS more functional

17 Alternative solutions result from a mismatch between the implementation of the new IS and usability 18 Highlights the importance of identifying the causes of the manifestation of workaround behavior to redefine the processes
Table V.

19 Workaround behavior in health information systems (HIS) threatens the potential for efficiency gains 20
Main conclusions on workaround found on the articles Users have supported the enterprise system before implementation. However, when the system was implemented, employees resist to use the system

Source: Developed by the authors

inside one IS (Beijsterveld and Groenendaal, 2016). However, a topic that should be discussed since the planning phase of an ERP is when a company must adapt their business processes to the ERP system and when it must adapt their ERP system to their business processes (Malaurent and Avison, 2016). This appropriate reflection and planning can inhibit the manifestation of workaround, since workarounds can be much more than resistance acts and be, in fact, a necessary solution to support the accomplishment of activities (Azad and King, 2012). The negative impact of these organizational practices was debated by Ignatiadis and Nandhakumar (2009), the authors' study suggests that solutions may occur due to the user's ignorance regarding the system's functionality, as well as the uncertain requirements by the users during the implementation of the ERP system. The adoption of ERP often does not result in the expected outcome, and does not provide the promised benefits; this being the main reason for the developing of researches to determine why the use of an ERP is not always ideal (Grabski et al., 2011). Seeing as ERP are extremely complex, large investments are made and the response is often not according to what is expected.

Another frequent utilization of workaround in IS was on the healthcare context. Studies such as (Hooff and Hafkamp, 2017; Savoli et al., 2016; Reiz and Gewald, 2016; Röder et al., 2015; Burns et al., 2015; Safadi and Faraj, 2010) approach the topic. The security excess in a healthcare environment was addressed, as could bring 
consequences such as evoking negative emotions on the users in relation to the system, increasing of dissatisfaction and occurrence of workaround practices that may result in the ineffective use of the system and, occasionally, could endanger the patients' lives (Savoli et al., 2016). The creation of alternative workflows among healthcare professionals does not assure security information practices nor patient privacy, especially when involving information management decisions (e.g. information storage, recovery and/or transmission of patient data) (Burns et al., 2015). In fact, the complexity of the medical work and the software's incapacity to adapt to the different medical practices can explain the alternative practices on what concerns healthcare ISs (Safadi and Faraj, 2010). Thus, some healthcare professionals unsatisfied with the system find ways to avoid working with it (Reiz and Gewald, 2016).

Workaround in IS in the healthcare context was also studied as a breach, alternative practices being a great concern of this area. This issue addressed topics such as privacy of information, breach of information, preoccupation and impact on the healthcare context. According to the US Department of Health and Human Services, over 134 million patient information were breached since 2009, putting at risk the confidentiality of patient records, resulting in organizational consequences, with reputation damage, financial penalty and civil and criminal liabilities (Wall et al., 2015). According to a non-profit organization that maintains information on data breach updated in all industries in the USA, the health division has the most significant number of internal data breaches (Cleanringhouse, 2010). In some studies, the authors present aspects about the implementation of healthcare systems, a fact that brought unexpected consequences that lead to the resistance and application of alternative solutions by the users (Ash et al., 2007; Lapointe and Rivard, 2005). When new healthcare IS is implemented, the users may find challenges, caused by a number of reasons, for instance, inefficient process design, poor system usability, improper user training and rigid clinical guidelines (Vogelsmeier et al., 2008).

Furthermore, twelve articles deemed that the manifestation of the workaround behavior has a negative impact on the organizations, which may result in post-implementation malfunctions. The main reason which leads the authors of the selected articles to study workaround behavior was the need to define the reasons of the manifestation of the behavior to subsequently take measures to reduce its impact since the workaround behavior can create risks, inefficiency or errors, which may have an impact on work activities (Boudreau and Robey, 2005; Gasparas and Monteiro, 2009).

The main reason identified for the manifestation of the workaround behavior was to reduce technology restrictions for the accomplishment of tasks. Many alternative solutions occur because technology does not fit the realities and contingencies of daily work (Alter, 2014). Alternative solutions may be necessary for the users in the sense of supporting their daily activities (Azad and King, 2012) and facilitating users' interaction in the case of a poorly planned IS (Ferneley and Sobreperez, 2006). According to some authors' perspective, alternative solutions are inevitable inside organizations (Györy et al., 2012). If on the one hand, the unfavorable environment detects alternatives as breaching and resisting intentions, expectations and business process activities (Röder et al., 2015), on the other hand, the favorable environment suggests alternative solutions as essential sources to analyze and learn policies, procedures and impacting issues at work (Alter, 2014). Figure 4 presents a concept map of the most important aspects identified in the analysis of the 20 selected articles.

\section{Conclusions and guidelines for future research}

The objective of this study was to analyze how workaround behavior has been approached in IS studies with the intent of verifying its applicability and presenting recommendations for future research. Therefore, to reach this objective, a Systematic Review of the Literature was performed by selecting and subsequently analyzing 20 articles that present the term "workaround" in the IS field of knowledge.

Workaround behaviour 
REGE 25,4

\section{2}

Figure 4.

Concept map workaround behavior in IS

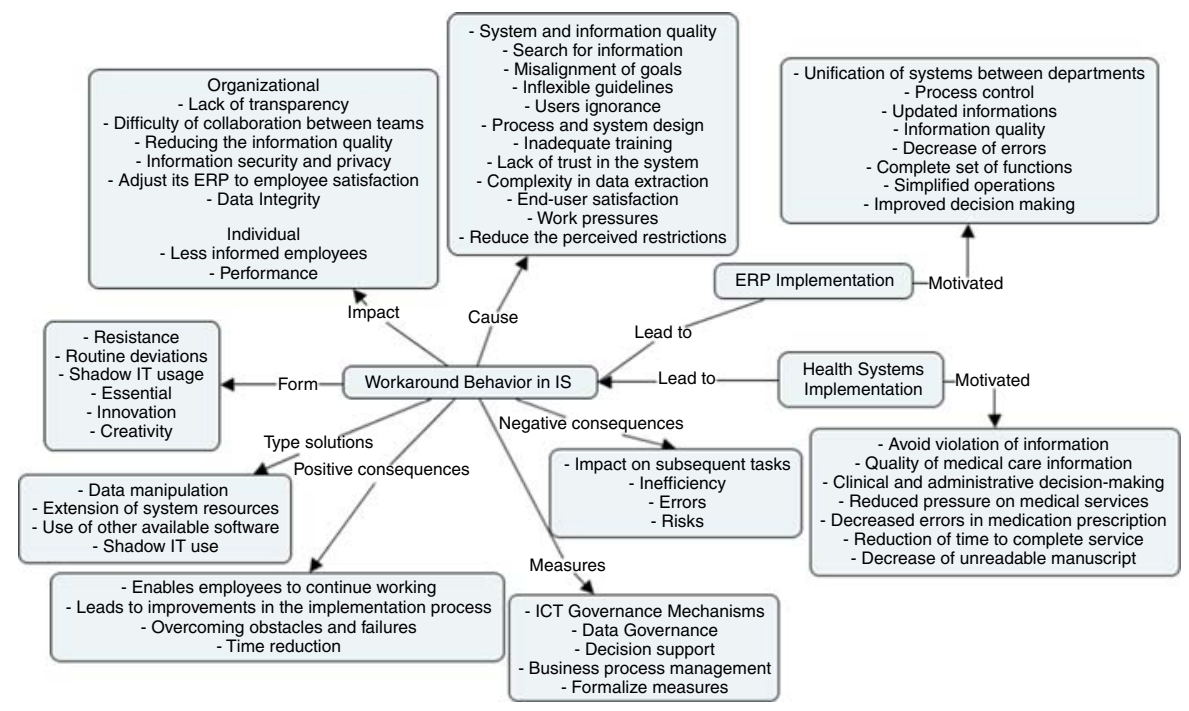

Source: Developed by the authors in Cmap Tools

Out of the 20 analyzed articles, 85 percent are empirical, revealing that the concern of most studies was to analyze how workaround behavior can affect organizations' daily activities to then take preventive or corrective measures regarding the workaround behavior. Through the analysis of the studies, we can infer that the main reason of the manifestation of workaround behavior is the users' dissatisfaction with the noticed limitations in the utilization of systems, corroborated by Laumer et al. (2017). From the twenty analyzed studies, eight addressed an implementation of ERP along with the workaround behavior, stating that after the implementation the workers adopted alternative solutions due to finding problems in the ERP system.

Through the literature review, we identified that workaround behavior has more negative consequences than positive ones, which can impact the organizations in an unsatisfactory manner. Silic and Back (2014) points out that organizations face large difficulties with relation to security risk because of workaround manifestation, specifically shadow IT systems resulting from the adoption of BYOD. Employees installed nonauthorized software in their own devices, sometimes unaware they are using unauthorized solutions. However, managing multiple levels of awareness and mitigation of information security risks of the final users when using mobile devices in organizations that adopted BYOD is an almost impossible task (Allam et al., 2014).

According to Bain and Taylor (2000), companies face a great challenge when they need to monitor or trace real work practices and, at the same time, allow the employees to work in a cooperative and flexible way. When there is a divergence between the expectations of the technology and the real work practices, the employees tend to implement alternative solutions, deviating from the pre-established procedures and not using the technology implemented by the company. Alternative solutions may produce different results for the actors involved: on one hand, the employees adopt an alternative solution according to their needs, with the finality of overcoming obstacles in their work activities. On the other hand, there is the organization's concerns about the risks related to the adoption of these solutions (Drum et al., 2016). The alternative solutions can be essential sources for analyzing and learning policies and procedures, or enabling a positive resistance ensuring the continuity of a work task (Campbell, 2011) or the unfavorable environment perceives alternative 
solutions as breaching and resisting business process standards and security policies restrictions (Boudreau and Robey, 2005).

Finally, we identified that there are few studies on workaround behavior in Brazil, revealing the need for studies on this subject. As discussed on the literature review and results sessions, workaround behavior can impact the organization in a negative way, spurring the incidence of errors and causing security and privacy risks.

In this manner, we suggest as future research a deeper research on the topic of the adoption of workaround, identifying which are the main variables that influence the manifestation of that behavior and how this behavior impacts positively and negatively the organizations. In Laumer et al. (2017) it was identified that the study obtained results that can be different in other IS and in industrial organizations or in organizations of different sizes in different cultural contexts, showing the importance of studies on companies inserted in different contexts. Besides that, we suggest a study that identifies the reason why, frequently, after the implementation of the systems, mainly, the ERP, the users tend to adopt alternative solutions. Our last suggestion implies in a study on the manifestation of workaround behavior under the light of the institutional theory, since this theory seeks to understand the processes and the structures of organizations, such as rules and routines established as guidelines to be followed, investigating how these elements become obsolete, being, in fact, similar to what happens to workaround behavior, which is considered a deviation from the routine and norms.

This article makes contributions in the theoretical and practical scope, bringing relevant concepts about workaround behavior, corroborating with the importance of the studies on workaround in the IS area. The literature review of the 20 articles analyzed contributes exposing the main features present in each article, such as theoretical and methodological aspects that support the research. Through this analysis, a conceptual map was developed presenting the most relevant points about workaround behavior, such as causes, instances, negative and positive consequences, the form that establishes the types of solutions and the organizational and individual impact are presented.

As managerial contributions, this study supports managers to understand the factors related to the use of alternative solutions by employees, allowing the identification of the causes and some negative and positive consequences. In that sense, the results of this research can help managers to cope with this phenomenon increasingly present within organizations by allowing them to develop more effective measures, policies, and strategies in order to avoid or minimize this behavior. If on the one hand alternative practices can provide superior individual performance, on the other hand it can be avoided by organization because of the risks.

\section{References}

Alalwan, J.A. and Weistroffer, H.R. (2012), "Enterprise content management research: a comprehensive review", Journal of Enterprise Information Management, Vol. 25 No. 5, pp. 441-461, doi: 10.1108/ 17410391211265133.

Allam, S., Flowerday, S.V. and Flowerday, E. (2014), "Smartphone information security awareness: a victim of operational pressures", Computers \& Security, Vol. 42, pp. 56-65, doi: 10.1016/j.cose.2014.01.005.

Alojairi, A. (2017), "The dynamics of IT workaround practices a theoretical concept and an empirical assessment", International Journal of Advanced Computer Science and Applications, Vol. 8 No. 7 , pp. 527-534.

Alter, S. (2014), "Theory of workarounds", Communications of the Association for Information Systems, Vol. 34 No. 1, pp. 1041-1066.

Alvarez, R. (2008), "Examining technology, structure and identity during an enterprise system implementation", Information Systems Journal, Vol. 18 No. 2, pp. 203-224, doi: 10.1111/ j.1365-2575.2007.00286.x. 
REGE 25,4
Ash, J.S., Sittig, D.F., Poon, E.G., Guappone, K., Campbell, E. and Dykstra, R.H. (2007), "The extent and importance of unintended consequences related to computerized provider order entry", Journal of the American Medical Informatics Association, Vol. 14 No. 4, pp. 415-423, doi: 10.1197/jamia.M2373.

Azad, B. and King, N. (2008), "Enacting computer workaround practices within a medication dispensing system", European Journal of Information Systems, Vol. 17 No. 3, pp. 264-278, doi: 10.1057/ejis.2008.14.

Azad, B. and King, N. (2012), "Institutionalized computer workaround practices in a Mediterranean country: an examination of two organizations", European Journal of Information Systems, Vol. 21 No. 4, pp. 358-372, doi: 10.1057/ejis.2011.48.

Bain, P. and Taylor, P. (2000), "Entrapped by the 'electronic panopticon'? Worker resistance in the call centre”, New Technology, Work and Employment, Vol. 15 No. 1, pp. 2-18, doi: 10.1111/1468-005X.00061.

Beijsterveld, J.A. and Groenendaal, W.J.V. (2016), "Solving misfits in ERP implementations by SMEs", Information Systems Journal, Vol. 26 No. 4, pp. 369-393, doi: 10.1111/isj.12090.

Biolchini, J.C.A., Mian, P.G., Natali, A.C.C., Conte, T.U. and Travassos, G.H. (2007), "Scientific research ontology to support systematic review in software engineering", Advanced Engineering Informatics, Vol. 21 No. 2, pp. 133-151, doi: 10.1016/j.aei.2006.11.006.

Boudreau, M.C. and Robey, D. (2005), "Enacting integrated information technology: a human agency perspective”, Organization Science, Vol. 16 No. 1, pp. 3-18, doi: 10.1287/orsc.1040.0103.

Burns, A.J., Young, J., Roberts, T.L., Courtney, J.F. and Ellis, T.S. (2015), "Exploring the role of contextual integrity in electronic medical record (EMR) system workaround decisions: an information security and privacy perspective", AIS Transactions on Human-Computer Interaction, Vol. 7 No. 3, pp. 142-165.

Campbell, D. (2011), "Policy workaround stories are valuable evaluative indicators: but should they be told?", American Journal of Evaluation, Vol. 32 No. 3, pp. 408-417, doi: 10.1177/1098214011405505.

Choudrie, J. and Zamani, E.D. (2016), "Understanding individual user resistance and workarounds of enterprise social networks: the case of Service Ltd”, Journal of Information Technology, Vol. 31 No. 2, pp. 130-151, doi: 10.1057/jit.2016.9.

Clearinghouse, P.R. (2010), "Chronology of data breaches: security breaches 2005-present”, available at: www.privacyrights.org/data-breach (accessed November, 2017).

Courtright, J.F., Acton, W.H., Frazier, M.L. and Lane, J.W. (1988), "Effects of 'workarounds' on perceptions of problem importance during operational test", Proceedings of the Human Factors Society Annual Meeting, Vol. 32 No. 17, pp. 1150-1153, doi: 10.1177/154193128803201705.

Cresswell, K.M., Mozaffar, H., Lee, L., Williams, R. and Sheikh, A. (2016), "Workarounds to hospital electronic prescribing systems: a qualitative study in English hospitals", BMJ Quality \& Safety.

Drum, D.M., Pernsteiner, A.J. and Revak, A. (2016), "Walking a mile in their shoes: user workarounds in a SAP environment", International Journal of Accounting \& Information Management, Vol. 24 No. 2, pp. 185-204, doi: 10.1108/IJAIM-09-2015-0059.

Drum, D.M., Pernsteiner, A.J. and Revak, A. (2017), "Workarounds in an SAP environment: impacts on accounting information quality", Journal of Accounting \& Organizational Change, Vol. 13 No. 1, pp. 44-64, doi: 10.1108/JAOC-05-2015-0040.

Dulipovici, A. and Vieru, D. (2016), "BYOD-enabled workarounds: a process perspective", Proceedings of the 22nd Americas Conference on Information Systems, Association for Information Systems, San Diego, CA, August.

Ferneley, E.H. and Sobreperez, P. (2006), "Resist, comply or workaround? An examination of different facets of user engagement with information systems", European Journal of Information Systems, Vol. 15 No. 4, pp. 345-356, doi: 10.1057/palgrave.ejis.3000629.

Foshay, N. and Kuziemsky, C. (2014), "Towards an implementation framework for business intelligence in healthcare", International Journal of Information Management, Vol. 34 No. 1, pp. 20-27, doi: 10.1016/j.ijinfomgt.2013.09.003.

Gartner (2018), "Gartner says global IT spending to reach $\$ 3.7$ trillion in 2018", available at: www.gartner.com/newsroom/id/3845563 (accessed November, 2018). 
Gasparas, J. and Monteiro, E. (2009), "Cross-contextual use of integrated information systems", Europeean Conference on Information Systems Proceedings, Verona, June.

Gasser, L. (1986), "The integration of computing and routine work", ACM Transactions on Information Systems, Vol. 4 No. 3, pp. 205-225, doi: 10.1145/214427.214429.

Grabski, S.V., Leech, S.A. and Schmidt, P.J. (2011), "A review of ERP research: a future agenda for accounting information systems", Journal of Information Systems, Vol. 25 No. 1, pp. 37-78, doi: 10.2308/jis.2011.25.1.37.

Györy, A.A.B., Cleven, A., Uebernickel, F. and Brenner, W. (2012), "Exploring the shadows: IT governance approaches to user-driven innovation", 20th European Conference on Information Systems (ECIS), Barcelona, June.

Hooff, V.D.B. and Hafkamp, L. (2017), "Dealing with dissonance: misfits between an EHR system and medical work practices", ICIS, Seoul, December.

Huuskonen, S. and Vakkari, P. (2013), “'I Did It My Way': social workers as secondary designers of a client information system”, Information Processing \& Management, Vol. 49 No. 1, pp. 380-391, doi: 10.1016/j.ipm.2012.05.003.

Ignatiadis, I. and Nandhakumar, J. (2009), "The effect of ERP system workarounds on organizational control: an interpretivist case study", Scandinavian Journal of Information Systems, Vol. 21 No. 2, pp. 1-32.

Kobayashi, M., Fussell, S.R., Xiao, Y. and Seagull, F.J. (2005), "Work coordination, workflow, and workarounds in a medical context", Conference on Human Factors in Computing Systems, CHI 2005, Portland, OR, April.

Lapointe, L. and Rivard, S. (2005), "A multilevel model of resistance to information technology implementation”, MIS Quarterly, Vol. 29 No. 3, pp. 461-491, doi: 10.2307/25148692.

Laumer, S., Maier, C. and Weitzel, T. (2017), "Information quality, user satisfaction, and the manifestation of workarounds: a qualitative and quantitative study of enterprise content management system users", European Journal of Information Systems, Vol. 26 No. 4, pp. 333-360, doi: 10.1057/s41303-016-0029-7.

Lund-Jensen, R., Azaria, C., Permien, F.H., Sawari, J. and Bækgaard, L. (2016), "Feral information systems, shadow systems, and workarounds-a drift in IS terminology", Procedia Computer Science, Vol. 100, pp. 1056-1063, doi: 10.1016/j.procs.2016.09.281.

Malaurent, J. and Avison, D. (2015), "From an apparent failure to a success story: ERP in China-post implementation", International Journal of Information Management, Vol. 35 No. 5, pp. 643-646, doi: 10.1016/j.ijinfomgt.2015.06.004.

Malaurent, J. and Avison, D. (2016), "Reconciling global and local needs: a canonical action research project to deal with workarounds", Information Systems Journal, Vol. 26 No. 3, pp. 227-257, doi: $10.1111 /$ isj.12074.

Monteiro, E., Jarulaitis, G. and Hepsø, V. (2012), "The family resemblance of technologically mediated work practices", Information and Organization, Vol. 22 No. 3, pp. 169-187, doi: 10.1016/j. infoandorg.2012.03.001.

Orlikowski, W.J. (2008), "Using technology and constituting structures: a practice lens for studying technology in organizations", in Halverson, A. and Kellogg, E. (Eds), Resources, Co-evolution and Artifacts, Springer, London, pp. 255-305, doi: 10.1007/978-1-84628-901-9_10.

Parks, R., Xu, H., Chu, C.H. and Lowry, P.B. (2017), "Examining the intended and unintended consequences of organisational privacy safeguards", European Journal of Information Systems, Vol. 26 No. 1, pp. 37-65, doi: 10.1057/s41303-016-0001-6.

Petrides, L.A., McClelland, S.I. and Nodine, T.R. (2004), "Costs and benefits of the workaround: inventive solution or costly alternative", International Journal of Educational Management, Vol. 18 No. 2, pp. 100-108, doi: 10.1108/09513540410522234.

Petter, S., DeLone, W. and McLean, E.R. (2013), "Information systems success: the quest for the independent variables", Journal of Management Information Systems, Vol. 29 No. 4, pp. 7-62, doi: 10.2753/MIS0742-1222290401. 
REGE 25,4

Reiz, A. and Gewald, H. (2016), "Physicians' resistance towards information systems in healthcare: the case of workarounds”, PACIS, June, Taiwan, p. 12.

Rikhardsson, P. and Dull, R. (2016), "An exploratory study of the adoption, application and impacts of continuous auditing technologies in small businesses", International Journal of Accounting Information Systems, Vol. 20, pp. 26-37, doi: 10.1016/j.accinf.2016.01.003.

Röder, N., Wiesche, M., Schermann, M. and Krcmar, H. (2015), "Workaround aware business process modeling", 12th International Conference on Wirtschaftsinformatik, March.

Safadi, H. and Faraj, S. (2010), "The role of workarounds during an OpenSource electronic medical record system implementation", ICIS, p. 47.

Savoli, A., Addas, S. and Fagnot, I. (2016), "Too much of a good thing? An investigation of the negative consequences of information security in a healthcare setting", Pre-ICIS Workshop on Information Security and Privacy (SIGSEC), October.

Scholl, H.J. and AlAwadhi, S. (2016), "Creating smart governance: the key to radical ICT overhaul at the city of Munich", Information Polity, Vol. 21 No. 1, pp. 21-42, doi: 10.3233/IP-150369.

Silic, M. and Back, A. (2014), "Shadow IT-a view from behind the curtain", Computers \& Security, Vol. 45, pp. 274-283, doi: 10.1016/j.cose.2014.06.007.

Urus, S.T., Molla, A. and Teoh, S.Y. (2011), "Post-ERP feral system taxonomy: a manifestation from multiple case studies", The European Conference on Information Systems Management, September, p. 458.

Vaezi, R., Mills, A., Chin, W. and Zafar, H. (2016), "User satisfaction research in information systems: historical roots and approaches”, CAIS, Vol. 38, pp. 27, doi: 10.17705/1CAIS.03827.

Vogelsmeier, A.A., Halbesleben, J.R. and Scott-Cawiezell, J.R. (2008), "Technology implementation and workarounds in the nursing home", Journal of the American Medical Informatics Association, Vol. 15 No. 1, pp. 114-119, doi: 10.1197/jamia.M2378.

Wall, J., Lowry, P.B. and Barlow, J.B. (2015), “Organizational violations of externally governed privacy and security rules: explaining and predicting selective violations under conditions of strain and excess", Journal of the Association for Information Systems, Vol. 17 No. 1, pp. 39-76.

Webster, J. and Watson, R.T. (2002), "Analyzing the past to prepare for the future: writing a literature review”, MIS Quarterly, Vol. 26 No. 2, pp. xiii-xxiii, doi: 10.2307/4132319.

Xiong, J. and Qureshi, S. (2012), "Analysis of information and communications technology adoption between small businesses in China and the United States", Information Systems and Quantitative Analysis Faculty Proceedings \& Presentations, p. 51.

Yang, Z., Ng, B.Y., Kankanhalli, A. and Yip, J.W.L. (2012), "Workarounds in the use of IS in healthcare: a case study of an electronic medication administration system", International Journal of Human-Computer Studies, Vol. 70 No. 1, pp. 43-65, doi: 10.1016/j.ijhcs.2011.08.002.

Zimmermann, S., Rentrop, C. and Felden, C. (2017), "A multiple case study on the nature and management of shadow information technology", Journal of Information Systems, Vol. 31 No. 1, pp. 79-101, doi: 10.2308/isys-51579.

\section{Further reading}

DeLone, W.H. and McLean, E.R. (1992), "Information systems success: the quest for the dependent variable”, Information Systems Research, Vol. 3 No. 1, pp. 60-95, doi: 10.1287/isre.3.1.60.

\section{Corresponding author}

Aline de Vargas Pinto can be contacted at: alinevargas01@hotmail.com

For instructions on how to order reprints of this article, please visit our website:

www.emeraldgrouppublishing.com/licensing/reprints.htm

Or contact us for further details: permissions@emeraldinsight.com 